\title{
IMPACT OF PERMANENT BED RENOVATION PRACTICE ON IRRIGATION PERFORMANCE AND PRODUCTIVITY
}

\author{
Ghani Akbar ${ }^{1}$, Greg Hamilton ${ }^{2}$, Allen David McHugh ${ }^{3}$ and Steven Raine ${ }^{4}$ \\ ${ }^{1}$ Climate, Energy and Water Research Institute (CEWRI), National Agricultural Research Centre (NARC), \\ Islamabad, Pakistan; ${ }^{2}$ Maximum Soil \& Water Productivity Pty Ltd. Perth WA, Australia; ${ }^{3}$ CIMMYT- China, \\ Ningxia Academy of Agriculture and Forestry Sciences, Yinchuan, P.R. China; ${ }^{4}$ National Centre for Engineering in \\ Agriculture (NCEA), University of Southern Queensland (USQ), Toowoomba, Australia \\ Corresponding author's e-mail: ghani_akbar@hotmail.com
}

\begin{abstract}
Renovating permanent raised beds (PRB) generally aims to restore shape and increase water infiltration. However, their impact on irrigation performance and productivity in clay soil are unknown. Therefore, no-tillage (NT), shallow cultivation (SC) and blade loosening (BL) renovation methods were evaluated on a corn crop in clay (Vertisol). Results showed optimal irrigation performance (irrigation efficiencies and uniformity $>70 \%$ ) for the NT treatment and significantly lower application efficiency $(E a)$ for the SC and BL treatments. However, the BL treatment significantly increased the lateral infiltration thus wetted the 2 $\mathrm{m}$ wide beds during the normal irrigation periods. Similarly, the $0-30 \mathrm{~cm}$ bulk density profiles of the BL treatment were significantly less than that of the NT and SC treatments throughout the experimental period. However, BL treatment has shown the potential to increase water productivity (WP) up to 7\% when compared with NT treatment. Modelling showed Ea for the $\mathrm{SC}$ and BL treatments could be improved to effectively equal that of the NT treatment by increasing (up to double) the inflow rate $(Q)$ and reducing (up to half) time to cut-off $(T c o)$. Thus, the BL treatment can quickly enhance lateral infiltration in subsided wide beds in Vertisol at no significant trade-off and has the potential to enhance productivity.
\end{abstract}

Keywords: No tillage, shallow cultivation, blade loosening, bulk density, irrigation, application efficiency

\section{INTRODUCTION}

The permanent raised bed (PRB) farming is comprised of a bed-furrow system in which the beds and furrows are kept permanently in place and soil disturbance is minimized during sowing operations (McGarry, 1995; McKenzie, 1998; Cooper, 1999). Bed and furrow renovation is conducted only when necessary to restore them to optimal dimensions, loosen the subsided or slumped beds and control weeds, diseases and pests (Wightman et al., 2005). Complete reworking and reforming, or "knocking down", of beds is done only when judged to be necessary, and this ranges from once in two years (Cooper, 1999) to once in 18 years (Hulugalle et al., 2004). By including the principles of conservation agriculture, PRB farming minimises soil structural degradation and losses due to seepage and evaporation (Hulugalle and Daniells, 2005). Notwithstanding this, irrigated PRB systems should be in their infancy (Roth et al., 2005) and the benefits of refinements to PRB management practices need to be demonstrated to accelerate adoption.

The PRB renovation methods vary around the globe (Roth $e t$ al., 2005) and depend on traditional practices, farmer preferences, crop and available machinery. In majority of cases, PRB renovation involves surface soil disturbance and inversion. However, soil disturbance/inversion degrades soil structure and biology (Soane, 1976; Tullberg and Murray,
1988; McHugh et al., 2009; Wang et al., 2012). Deep blade (horizontal blade that cut the bed at their base) loosening, a form of bed renovation with effectively little to no soil inversion has been shown to improve and deepen root proliferation and increase soil organic matter in the duplex soils of Western Australia (Hamilton et al., 2005) and in the sandy clay loams of Asia (Jin et al., 2007; Akbar et al., 2009). Studies on impact of renovation practices on irrigation performance and productivity of heavier clay soils, such as Vertisol, have not been recorded. Hence, this study has sought to quantify the impact of PRB renovations on irrigation, soil infiltration and production performance of PRBs on a Vertisol in Australia.

\section{MATERIALS AND METHODS}

Site description: The research site was located near Cambooya in South East Queensland $\left(27.734900^{\circ} \mathrm{S}\right.$, $\left.151.828062^{\circ} \mathrm{E}\right)$. A brief description of the research site including topography, soil type and climatic conditions is given in Table 1. Prior to the experimentation the field was under conservation agriculture for the last 35 years with $2 \mathrm{~m}$ spaced beds and furrows $10 \mathrm{~cm}$ deep, with $40 \mathrm{~cm}$ top widths and $465 \mathrm{~m}$ lengths. Irrigation water was applied to the furrows from the distribution canal through seven metre long siphon tubes (50 $\mathrm{mm}$ diameter). 
Table 1. Location and description of research site.

\begin{tabular}{ll}
\hline Characteristic & Description \\
\hline Country, Province & Australia, south east Queensland \\
Location & $27.734900^{\circ} \mathrm{S}, 151.828062^{\circ} \mathrm{E}$ \\
Elevation above msl & $454 \mathrm{~m}$ \\
Field slope & $0.002 \mathrm{~m} \mathrm{~m}^{-1}$ \\
Ann. mean rain $(\mathrm{mm})$ & 737 \\
Ann. median rain $(\mathrm{mm})$ & 620 \\
Ann. mean max. temp & $23^{\circ} \mathrm{C}$ \\
Ann. mean min. temp & $12.5^{\circ} \mathrm{C}$ \\
Soil type & Heavy clay Vertisol with shrink- \\
& swell properties \\
Cropping systems & Wheat, corn, millet, beans, hemp \\
\hline
\end{tabular}

Soil and crop management: The details of the three PRB renovation treatments employed were:

No tillage (NT) - furrows reshaped and the only soil disturbance in the bed occurred in the sown rows, (Fig. 1a).

Shallow cultivation (SC) - furrows reshaped and the top of the bed cultivated to a depth of about $10-15 \mathrm{~cm}$ before seeding (Fig. 1b).

Blade loosening (BL) - furrows reshaped and the soil was loosened by the action of sharp horizontal blades that are passed through the base of the bed at a $\sim 30 \mathrm{~cm}$ depth. This operation lifted and dropped the soil without disturbing the roots of the previous crop or causing any soil inversion (Fig. 1c).

(a)

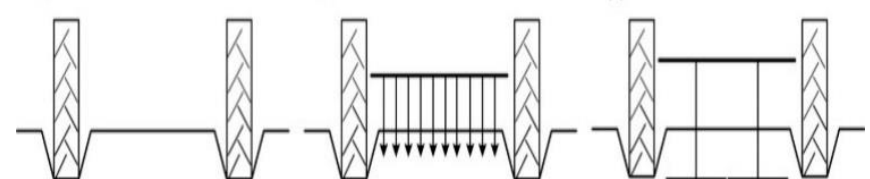

Figure 1.Layout of three PRB renovation methods including (a) NT: no tillage, (b) SC: shallow cultivation and (c) BL: blade loosening treatments.

The soil management treatments were imposed in a randomized (block) design with three replicates. The corn crop was planted on 3 October 2011 and harvested on 15 February 2012. The same crop agronomy (seed rate, fertilizer, and weedicide) was applied to all treatments.

Agronomic data collection included (land preparation practices, inputs applied, grain yield), local weather data from an automatic weather station, furrow slope and shape before irrigation. Three plant biomass samples from head, middle and tail sections of each treatment, with their three replications, were collected at crop harvest. The number of plants and the weight of the $1 \mathrm{~m}$ crop row were also recorded. The samples were dried in an oven at $45^{\circ} \mathrm{C}$ for one to two weeks before the final dry weight was recorded.
Irrigation management: Two irrigations were applied during the season. Irrigation applications were managed by controlling inflow rate (Q) and time to cut-off (Tco). Applications were stopped when the furrows were filled with water before the beds overtopped at the bottom end of the field. Irrigation management aimed to maximize the water productivity (WP) based on experience. Particularly, the Q to the BL furrows was increased relative to the other treatments by increasing the head in the supply channel.

\section{Experimental methods}

Soil Structure: The soil bulk density was used as an index of the porosity and the stability of soil structure by the timing (pre-seeding and post-harvest). The soil bulk density was recorded at sowing, before each irrigation and at harvest, using a gravimetric method and soil cores $(5 \mathrm{~cm} \times 5 \mathrm{~cm})$ collected from $0-30 \mathrm{~cm}$ profile depth at $10 \mathrm{~cm}$ intervals. A total of nine samples ( 3 per replicate) were collected from the head, middle and tail sections of each treatment, positioned near the centre of the bed. The soil moisture and bulk density were calculated on oven dry mass basis after drying at $105^{\circ} \mathrm{C}$ for 48 hours.

Soil moisture and infiltration: The bulk density samples collected at sowing, before irrigations and at harvest were also analyzed for gravimetric soil moisture content during the crop season. Additional soil moisture data of $100 \mathrm{~cm}$ profile across the bed during irrigation was collected using soil moisture meter (Micro-Gopher) with a set of three access tubes $(2 \mathrm{~cm}$ diameter) installed at $33 \mathrm{~cm}, 67 \mathrm{~cm}$ and $100 \mathrm{~cm}$ distance from furrow centre. This set up was replicated thrice for each treatment during both irrigation applications. The soil moisture data of $100 \mathrm{~cm}$ profile at $10 \mathrm{~cm}$ depth interval was recorded at 15 minutes intervals during the first hour of irrigation, 30 minutes during the second and third hour and then at one hour interval till the end of irrigation. This soil moisture data was used for identifying lateral wetting potential of the three renovation treatments.

Irrigation application and water productivity: The irrigation data collected included each furrow $Q$, water advance time at $100 \mathrm{~m}$ intervals along each furrow length and Tco. These were measured by the IRRIMATE ${ }^{\mathrm{TM}}$ suite of equipment developed at the National Centre for Engineering in Agriculture (NCEA), University of Southern Queensland (USQ), Toowoomba.

The water productivity (WP) was calculated as the ratio between the dry weight of crop yield (grain or straw) per unit area and the total seasonal water input per unit area. The total water input was calculated as the sum of seasonal rainfall and irrigation applications.

Irrigation performance modeling: The measured furrow dimensions (top, middle and bottom widths and furrow depth), $Q$, water flow advance readings and furrow slope were used to parameterize the inverse solution, volume balance soil infiltration model IPARM (Gillies and Smith, 2005) to determine the infiltration parameters $a, k$ and $f_{0}$ in the 
modified Kostiakov cumulative infiltration equation (Khatri, 2007; Gillies, 2008).

The IPARM output along with the furrow spacing, Tco and root zone soil moisture deficit $(S M D)$ were used to parameterize the surface irrigation model SIRMOD III (Dalton et al., 2001; Walker, 2003; Smith et al., 2005). SIRMOD was matched with field data by adjusting the Manning $n$ value from the default (i.e. $n=0.04$ ) until the simulated advance time at the end of the field equaled the measured advance time (McClymont and Smith, 1996). In all cases, the adjustments were small within the range of values for bare furrows.

The matched SIRMOD model was then used to evaluate each irrigation event in terms of: (i) Application efficiency (Ea) the ratio of irrigation water available to the crop in the root zone and the water received at the field inlet (ii) Requirement efficiency $(E r)$ - the ratio of volume of water stored in the root zone immediately after irrigation to the pre-irrigation root zone soil moisture deficit and (iii) Distribution uniformity $(D U)$ - the average depth of infiltrated water in the lower one quarter of the field divided by the average infiltrated depth of water over the whole field (Merriam and Keller, 1978). Deep drainage potential due to irrigation excess (DD) was calculated using the procedure of Smith et al. (2005). SIRMOD was also used to optimise irrigation performance by changing the $Q$ and $T c o$ in the model to maximize $E a$ and $E r$ values. Water reached the tail end of the furrow and did not overtop the beds. The optimization required meeting the $S M D$ and maximizing lateral infiltration, to maximize the use of inseason rainfall and minimize the occurrence of dry sections within the field.

Data analysis: ANOVA analysis was conducted on all data collected using IBM SPSS version 19. A general linear model (univariate) was used along with multiple comparisons using Tukey analysis, to identify significant differences between treatments as groups.

\section{RESULTS}

Soil Structure: The bulk density data (Fig. 2a) over the season (means from the samplings at sowing, before each irrigation and harvest) illustrates the effects of varying degrees of soil disturbance on the stability of soil structure. Average bulk density of BL was consistently lower than that from the SC and NT treatments, indicating a comparatively more loosened and stable structure. The bulk density of the BL treatment was significantly less than the SC and NT treatments over the 0$20 \mathrm{~cm}$ depth interval (Fig. 2b) but was not considerably $(\mathrm{P}=0.05)$ different in the $20-30 \mathrm{~cm}$ depth interval. Comparing data at sowing and at harvest indicated $\sim 5 \%, \sim 9 \%$ and $\sim 7 \%$ increase in average bulk density of 0-30 cm layer for the NT, $\mathrm{SC}$ and BL treatments, respectively.
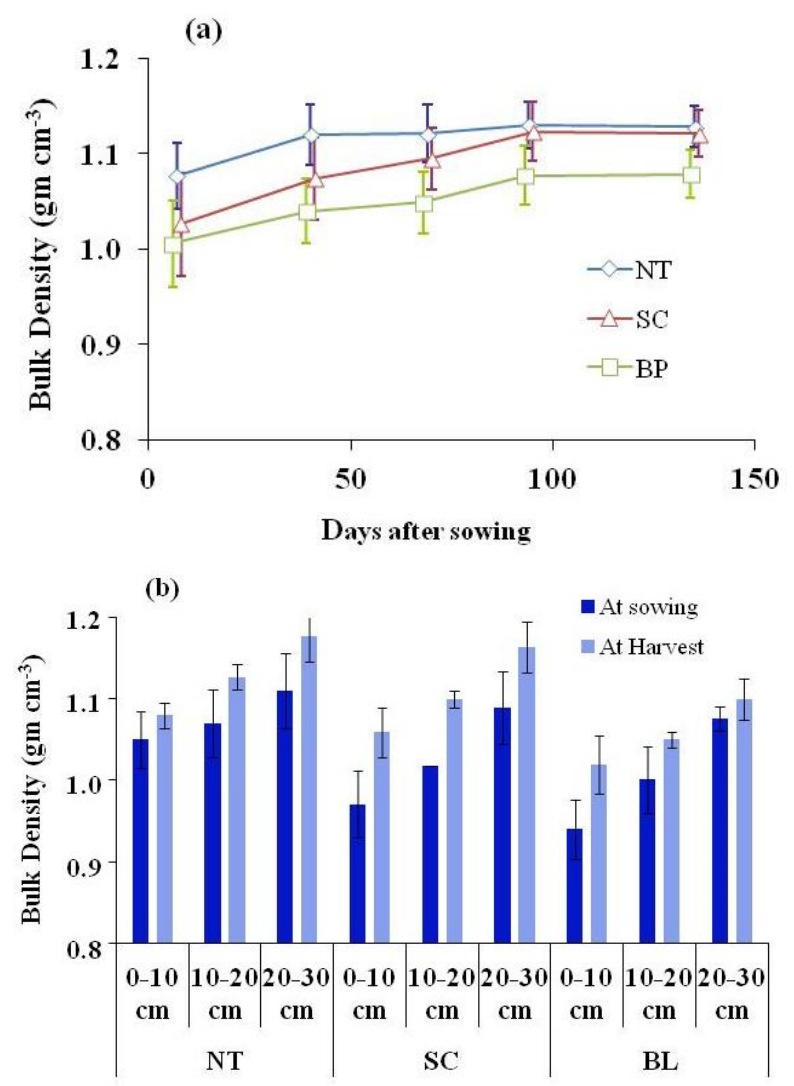

Figure 2. Temporal changes in average soil bulk densities of 0-30 $\mathrm{cm}$ profile during the season (a) and at sowing and harvest (b) under three PRB renovation treatments (vertical bars show $\mathrm{SD}$ ).

Soil moisture and infiltration: The soil moisture deficit (SMD) ranged 61 to $74 \mathrm{~mm}$ before the first irrigation and 106 to $134 \mathrm{~mm}$ before the second irrigation. There was sufficient time before the first and second irrigation for the renovation methods to influence the SMD. Therefore, the SMD in the BL treatment prior to the second irrigation was significantly less ( $21 \%$ or $\sim 28 \mathrm{~mm}$ less) than the SMD of the SC and NT treatments (Fig. 3).

The renovation method also affected the lateral infiltration rates to the centre of the beds. For instance, during the first irrigation the average times to wet the bed middles to field capacity were; $\mathrm{BL}=7 \mathrm{hrs}$; $\mathrm{SC}=9 \mathrm{hrs}$ and $\mathrm{NT}>10 \mathrm{hrs}$ (Fig. 4). The soil moisture of the entire bed was relatively even for the BL treatment when the wetting front reached the centre of the bed as compared to the NT and SC treatments. The differences in cumulative infiltration (Fig. 5) among the treatments show the effect of bulk density and $S M D$ of the renovation methods. The BL infiltration was significantly larger than the SC and NT treatments, which are not statistically different. The soil in the beds of the SC and NT 
treatments had a consolidated core and a similar or equal $S M D$, therefore with similar infiltration properties.

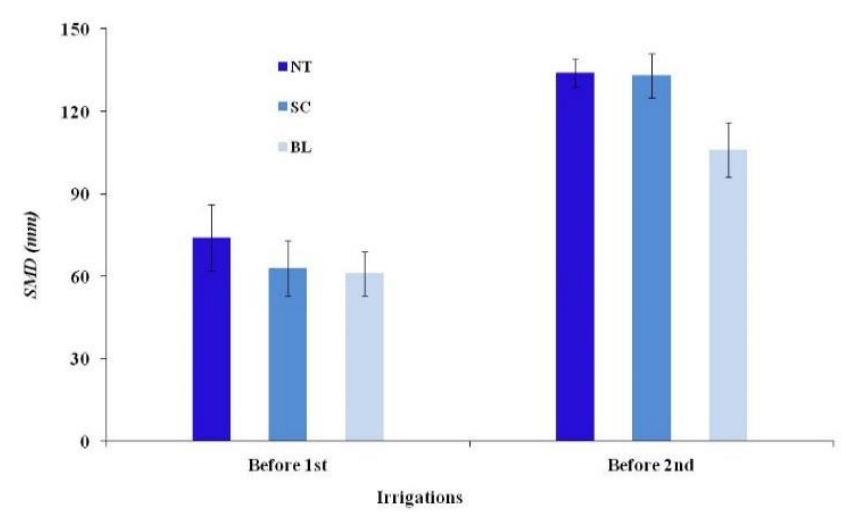

Figure 3. Average soil moisture deficit $(S M D)$ in $100 \mathrm{~cm}$ root zone profile prior to two irrigations of corn crop under three PRB renovation treatments (vertical bars show SD).
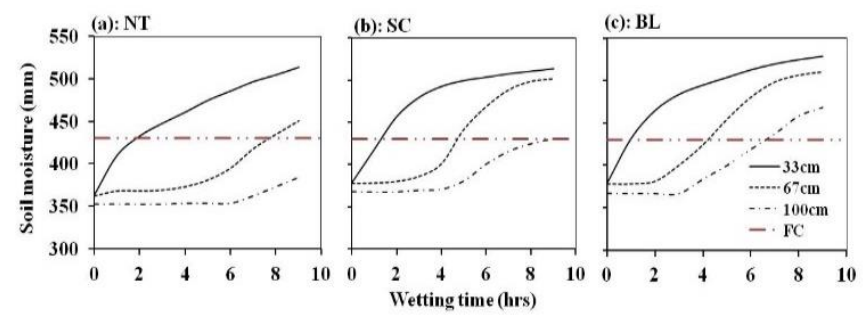

Figure 4. Volumetric soil moisture content of $100 \mathrm{~cm}$ profile at given distances from furrow centre during first irrigation to corn crop showing lateral infiltration potential of three PRB renovation treatments.

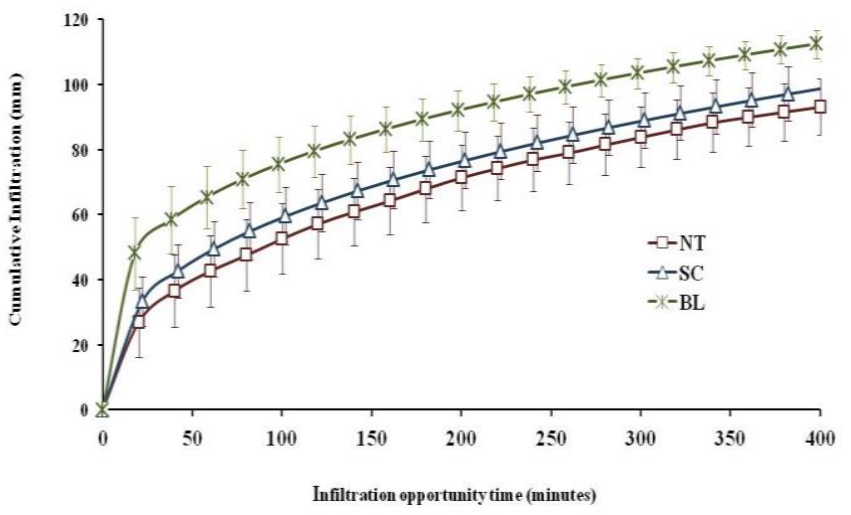

Figure 5. Average cumulative infiltration during two irrigations to corn crop under three PRB renovation treatments at given wetting time (Vertical bars show SD).
Irrigation application: Irrigation applications and rainfall during the cropping season is summarized in Table 2. The amount of extra irrigation water added to the BL and SC treatment remained well more than that applied to the NT treatment. For example, the average amount of water applied to the renovated treatments was significantly more than that applied to the NT treatments was; BL $13 \mathrm{~mm}$ (or 12\%), SC 10 $\mathrm{mm}$ (or 9\%). The enhanced lateral infiltration and extra water added caused the BL beds middle to be $\sim 4 \%$ moister than the NT treatment during the season.

Table 2. Irrigation applications to corn crop under three PRB renovation methods on a Vertisol (SD in brackets).

\begin{tabular}{lcrrr}
\hline $\begin{array}{l}\text { Treatment / } \\
\text { attributes }\end{array}$ & Irrigation \# & NT & SC & BL \\
\hline $\begin{array}{l}\text { Irrigation duration } \\
\text { (minutes) }\end{array}$ & 1st & 857 & 828 & 857 \\
Irrigation depth (mm) & 1st & 1013 & 1040 & 867 \\
& 2nd & 100 & 107 & 126 \\
& & 302 & 137 & 122 \\
Rainfall (mm) & & 526 & 546 & 302 \\
${ }^{*} T W I(\mathrm{~mm})$ & & & &
\end{tabular}

Irrigation performance modeling: Average irrigation data (Table 3) illustrate that more water was applied to the BL and $\mathrm{SC}$ treatments despite some increase to the $\mathrm{Q}$ on the $\mathrm{BL}$ and SC treatments to account for their greater sorptivity (Q for NT, $1.85 \mathrm{~L} \mathrm{~s}^{-1}$ compared to SC $2.02 \mathrm{~L} \mathrm{~s}^{-1}$ and BL $2.251 \mathrm{~L} \mathrm{~s}^{-1}$ ). The average irrigation volumes absorbed by the $\mathrm{BL}$ and $\mathrm{SC}$ treatments were $124 \mathrm{~mm}$ and $122 \mathrm{~mm}$, compared to the NT treatment of $112 \mathrm{~mm}$. The average deep drainage losses over those experienced by the NT treatment were $41 \mathrm{~mm}$ for BL and $18 \mathrm{~mm}$ for SC treatments. In consequence, the irrigation performance $(\mathrm{Ea})$ of these treatments was substantially poorer compared with the NT treatment.

When the irrigation data was subjected to optimization modelling, the need and value of increasing $Q$ and decreasing $T c o$ for highly sorptive soil conditions became apparent. To produce equal or greater values for $E a, E r$ and $D U ; Q$ rates effectively had to be doubled and Tco times more than halved. If such optimized practice was adopted for the BL and SC treatments it would make the amounts of water applied and lost in deep drainage effectively equal to those of the NT treatment.

Crop growth and production: There were slight increases in plant density, straw yield, and grain yield in favour of the BL treatment (Fig. 6), but none of these differences was statistically significant. The WP data (Table 4) shows that both the biomass and grain yield WP of the BL and SC treatments were comparable to the NT treatment. Had the irrigation practice been optimized on the BL treatment, the water applied would have been $95 \%$ (206 $\mathrm{mm}$ ) of that applied to the NT treatment $(218 \mathrm{~mm})$ and the biomass and grain yield 
Table 3. Impact of three PRB renovation methods and optimized $(Q$ and $T c o)$ on irrigation performance $(D D=$ deep drainage potential, $E a=$ application efficiency, $E r=$ requirement efficiency and $D U=$ distribution uniformity) during two irrigations to corn crop on a Vertisol (SD in brackets).

\begin{tabular}{lcccccc}
\hline Irrigation performance & \multicolumn{3}{c}{ Field measured } & \multicolumn{3}{c}{ Q \& Tco optimized } \\
\cline { 2 - 7 } parameter & NT & SC & BL & NT & SC & BL \\
\hline Field Length (m) & 465 & 465 & 465 & 465 & 465 & 465 \\
Furrow top width $(\mathrm{cm})$ & 53 & 49 & 61 & 53 & 49 & 61 \\
Furrow middle width $(\mathrm{cm})$ & 35 & 32 & 39 & 35 & 32 & 39 \\
Furrow bottom width $(\mathrm{cm})$ & 15 & 16 & 19 & 15 & 16 & 19 \\
Furrow depth $(\mathrm{cm})$ & 12 & 11 & 14 & 12 & 11 & 14 \\
$Q\left(\mathrm{~L} \mathrm{~s}^{-1}\right)$ & $1.85 \mathrm{a}(0.1)$ & $2.02 \mathrm{a}(0.1)$ & $2.25 \mathrm{a}(0.2)$ & $3.00 \mathrm{~b}(0.1)$ & $3.5 \mathrm{~b}(0.2)$ & $4.00 \mathrm{~b}(0.3)$ \\
$T c o($ min $)$ & $935 \mathrm{a}(22)$ & $934 \mathrm{a}(45)$ & $862 \mathrm{a}(67)$ & $564 \mathrm{~b}(21)$ & $483 \mathrm{~b}(12)$ & $399 \mathrm{~b}(19)$ \\
Inflow (mm/irrigation) & $112 \mathrm{a}(12)$ & $122 \mathrm{a}(13)$ & $124 \mathrm{a}(15)$ & $109 \mathrm{a}(42)$ & $109 \mathrm{~b}(27)$ & $103 \mathrm{~b}(50)$ \\
$D D(\mathrm{~mm} /$ irrigation) & $26 \mathrm{a}(3)$ & $44 \mathrm{a}(3)$ & $67 \mathrm{a}(3)$ & $15 \mathrm{a}(5)$ & $15 \mathrm{~b}(4)$ & $22 \mathrm{~b}(5)$ \\
$E a(\%)$ & $74 \mathrm{a}(2)$ & $59 \mathrm{a}(3)$ & $47 \mathrm{a}(2)$ & $86 \mathrm{a}(4)$ & $86 \mathrm{~b}(2)$ & $79 \mathrm{~b}(3)$ \\
$E r(\%)$ & $98 \mathrm{a}(2)$ & $99 \mathrm{a}(1)$ & $99 \mathrm{a}(1)$ & $94 \mathrm{a}(1)$ & $95 \mathrm{a}(2)$ & $99 \mathrm{a}(1)$ \\
$D U(\%)$ & $79 \mathrm{a}(3)$ & $78 \mathrm{a}(4)$ & $80 \mathrm{a}(3)$ & $82 \mathrm{a}(3)$ & $84 \mathrm{a}(3)$ & $86 \mathrm{~b}(2)$ \\
\hline
\end{tabular}

*Figures followed by different letters for the same treatment in rows are significantly different $(\mathrm{P}=0.05)$ between strategies.

WP would have been $29 \mathrm{~kg} \cdot \mathrm{ha}^{-1} \cdot \mathrm{mm}^{-1}$ and $18 \mathrm{~kg} \cdot \mathrm{ha}^{-1} \cdot \mathrm{mm}^{-1}$ (7\% and $6 \%$ higher than NT), respectively.

Table 4. Water input, crop yield and water productivity (WP; on dry biomass and dry grain yield basis) for corn crop under three PRB renovation methods on a Vertisol.

\begin{tabular}{lcccc}
\hline $\begin{array}{l}\text { Crop } \\
\text { Yield }\end{array}$ & Treat. & $\begin{array}{c}\text { Water } \\
\text { input }(\mathbf{m m})\end{array}$ & $\begin{array}{c}\text { Yield } \\
\left.\text { ton.ha-1 }^{-1}\right)\end{array}$ & $\begin{array}{c}\text { WP } \mathbf{( k g . h a}^{-\mathbf{1}} \\
\left.\mathbf{m m}^{-\mathbf{1}}\right)\end{array}$ \\
\hline Dry & NT & 526 & $14.07 \mathrm{a}$ & $27 \mathrm{a}$ \\
biomass & SC & 546 & $14.59 \mathrm{a}$ & $27 \mathrm{a}$ \\
& BL & 550 & $15.14 \mathrm{a}$ & $28 \mathrm{a}$ \\
Dry grain & NT & 526 & $8.94 \mathrm{a}$ & $17 \mathrm{a}$ \\
& SC & 546 & $9.13 \mathrm{a}$ & $17 \mathrm{a}$ \\
& BL & 550 & $9.24 \mathrm{a}$ & $17 \mathrm{a}$ \\
\hline
\end{tabular}

*Figures followed by different letters in columns for each crop season show significant $(\mathrm{P}=0.05)$ differences between treatments within the season.

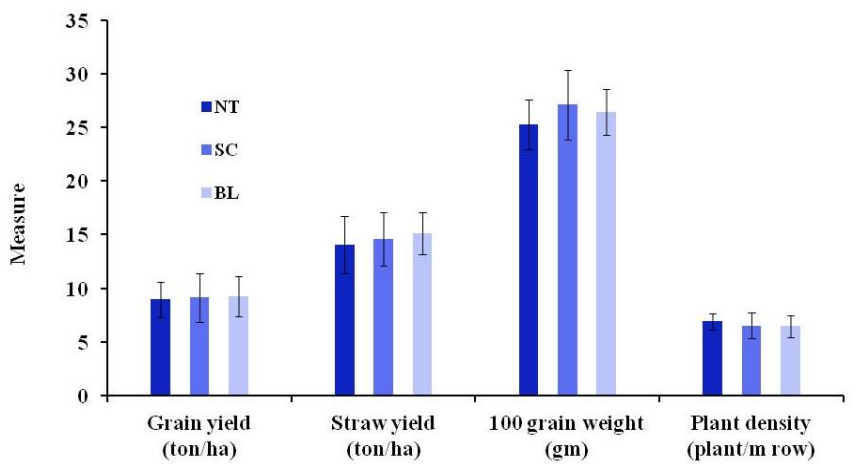

Figure 6. Comparative performance of corn crop on three PRB renovation treatments (vertical bars show SD).

\section{DISCUSSION}

Effect of bed renovation on irrigation management: The different bed renovation treatments resulted in different bulk densities (i.e. different pore size distributions and hydraulic properties), and soil structure stabilities. The increased structure stability and greater sorptivity of the BL treatment was due to non-inversion (McGarry, 1993) and the resulting undisturbed root material that acted as reinforcing rods (Hamilton et al., 2005) and provided greater shear resistance during wet soil conditions (Hamilton et al., 2014). This combination of factors that affected soil hydraulic properties provided the opportunity to assess the relative impact and importance of soil conditions that need to be considered when choosing the best irrigation practice to suit a particular set of circumstances.

The BL treatment produced the lowest BD profile, which enhanced lateral infiltration. The logical adjustment to irrigation practice to accommodate such conditions and maximize irrigation efficiency is to increase the inflow rate and reduce the time to cut off. This will shorten the opportunity time required for bed centres to reach field capacity. Similarly, the greater soil moisture holding capacity reduced irrigation demand before the second irrigation as evidenced through low soil moisture deficit for the BL treatment. This irrigation strategy ensures greater lateral infiltration, thus reducing the likelihood of deep drainage losses. The SC treatment with a shallower, similarly loose but less stable soil (Dunn et al., 1998; Coquet et al., 2005; Bormann and Klaassen, 2008) required intermediate adjustments to the optimum inflow rate and cut-off time.

The main practical advantage of the BL treatment is the speed and visibility of lateral infiltration of water to the bed centre. This allows the person managing the irrigation to use the 
merging of opposed wetting fronts in beds at the tail-end of the field, as a signal for the time to cut off the inflow. Also, the more rapid the inflow the lesser will be the time for infiltration of excessive amounts of water once the supply is cut off. Notwithstanding the reduced impact of managementinduced sorptivity differences in moist soil conditions, the enhanced lateral infiltration they will provide would still allow for the merging of wetting fronts at the tail-end of the beds to be used as a signal to cease the inflow.

Effects of bed renovation on crop production and WP: The measurable build-up of organic matter and soil structure stability resulting from enhanced root growth stimulated by the imposition of BL or the like treatments has been reported on many soils, farming systems and countries (Hassan et al., 2005; Hamilton et al., 2007; Jin et al., 2007), the assumption is reasonable that, over time, organic matter will increase and production benefits will derive from such a practice. Based on these reports and its proven ability of blade loosening to enhance the benefits of no-tillage conservation agriculture, the practice of such a bed renovation method is worth adopting for the long term. Combined with the knowledge of improved irrigation strategies for loose, structurally stable soils gained from this research, longer term improvements in WP should be assured, because improvements will occur in both the production and irrigation efficiency, as the optimized irrigation modelling has illustrated.

Increased crop yield and WP with reduced tillage compared with the conventional tillage intensive farming systems has been reported by Sayre et al. (2005) and Malhi et al. (2006). However, water availability to crops is the most yield limiting factor (Wang et al., 2011) and yield on the NT treatment under wider beds is more sensitive to lateral infiltration, as yield may be limited by the non-availability of nutrients (Wang et al., 2012) and lack of water for fulfilling the plant evapo-transpiration and metabolism needs. Reduced crop yield and $W P$ due to the poor lateral infiltration was also reported in several past studies, (Akbar et al., 2007; Jin et al., 2007) in sandy clay loam and by Lucy (1993) in Vertisol.

Although the BL and SC treatments mechanically loosened the subsided bed for improved infiltration, yield and WP were only slightly improved when compared with the NT treatment. One of the reasons may be the maize rows were on bed shoulders, thus the lack of wetting front movement to the bed middle in NT and SC treatments did not impacted on maize yield. Other reason may be the excessive irrigation application to $\mathrm{SC}$ and $\mathrm{BL}$ treatments may have negative consequences on crop yield and $W P$, as analytical correlations between crop yield and different irrigation performance parameters were established in many studies (Solomon, 1984; Holzapfel et al., 1985; Juan et al., 1996; Zhang et al., 1999). Therefore, improving irrigation performance with better management for both treatments will not only save water but may also contribute in yield increase, which can lead to improved WP. Higher yields, soil water storage, and WP on
BL were also reported in several studies (Eldridge and Robson, 1997; Hamilton et al., 2005; Jin et al., 2007; Akbar et al., 2009).

Research by Waldron and Dakessian (1981) and Tobias and Rickson (1994) has shown that roots significantly increase the shear strength of saturated soil and thereby increase soil stability, and this information has been used by Hamilton et al. (2005) to retain undisturbed roots in the top soil of BL treatment where they mimic reinforcing rods and maintain a stable structure during the wetting and draining.

Conclusions: The renovation practice of permanent raised beds can significantly impact on irrigation performance due to their influence on soil hydro-physical properties, thus may significantly influence the water productivity. The stable soil structure due to controlled renovation of permanent raised beds, e.g. blade loosening, may provide better rooting environment, which can be instrumental for increased crop production. Furthermore, the changed soil properties due to renovation practice requires optimized irrigation management, as per site specific conditions, for ensuring improved irrigation performance. However, further work is required to assess the benefits of different renovation methods over a longer period, to better define the optimal irrigation practice over a wider range of antecedent soil moisture conditions and the soil structure and crop production benefits that should result from enhanced root proliferation and retention.

Acknowledgement: The financial assistance of Australian Centre for International Agricultural Research (ACIAR) and farmer (David House) support in experiments is highly acknowledged.

\section{REFERENCES}

Akbar, G., G. Hamilton and Z. Hussain. 2009. Permanent Raised Bed Cropping System Improves Water Use Efficiencies of Wheat and Maize Crops, Mardan/Pakistan Experience. Pak. J. Water Resour. 13:17-24.

Akbar, G., G. Hamilton, Z. Hussain and M. Yasin. 2007. Problems and Potentials of permanent raised bed cropping systems in Pakistan. Pak. J. Water Resour.11:11-21.

Bormann, H. and K. Klaassen. 2008. Seasonal and land use dependent variability of soil hydraulic and soil hydrological properties of two northern German soils. Geoderma 145:295-302.

Cooper, J. 1999. A grower survey of rotations used in the New South Wales cotton industry. Aust. J. Exp. Agric. 39:743755 . 
Coquet, Y., P. Vachier and C. Labat. 2005. Vertical variation of near-saturated hydraulic conductivity in three soil profiles. Geoderma 126:181-191.

Dalton, P., S. R. Raine and K. Broadfoot. 2001. Best management practices for maximizing whole farm irrigation efficiency in the Australian Cotton industry. In: Final Report for CRDC Project NEC2C. Nat. Cen. for Eng. in Agric. USQ, Toowoomba.

Dunn, G., L. Ahuja, F. Fiedler, A. Garrison and J. Benjamin. 1998. Changes in soil water retention curves due to tillage and natural reconsolidation. Soil Sci. Soc. Amer. J. 62:1228-1233.

Eldridge, D. and A. Robson. 1997. Blade ploughing and exclosure influence soil properties in a semi-arid Australian woodland. J. Range Manage. 50:191-198.

Gillies, M. 2008. Managing the effect of infiltration variability on the performance of surface irrigation. Univ. of Southern Queensland (USQ), Toowoomba, Qld.

Gillies, M. and R. J. Smith. 2005. Infiltration parameters from surface irrigation advance and run-off data. Irrig. Sci. 24:25-35.

Hamilton, G., G. Akbar, I. Hassan, S. Raine, A. McHugh, P. Fisher, D. Bakker and J. Sheppard. 2014. Management to improve soil productivity and maximize lateral infiltration in permanent bed-furrow irrigation systems. In: Nat. Soil Sci. Conf., Soil Sci. Aust., MCG Melbourne, Victoria, Australia.

Hamilton, G., D. Bakker, D. Houlbrooke and C. Span. 2005. Raised Bed Farming in Western Australia. Dep. of Agric., Western Australia (Bull. 4646).

Hamilton, G., J. Sheppard and R. Bowey. 2007. Using controlled traffic to engineer seedbeds for increased water conservation, crop production and profit. In: $5^{\text {th }}$ Australian Controlled Traffic farming and Precision Agriculture Conference, Perth; pp.64-73.

Hassan, I., Z. Hussain and G. Akbar. 2005. Effect of permanent raised beds on water productivity for irrigated maize-wheat cropping system. In: C. Roth, R. Fischer and C. Meisner (eds.), Evaluation and performance of permanent raised bed cropping systems in Asia, Australia and Mexico. ACIAR Proceeding No 121, Griffith, NSW, Australia; pp.59-65.

Holzapfel, E.A., M.A. Marino and J. Chavez-Morales. 1985. Performance irrigation parameters and their relationship to surface-irrigation design variables and yield. Agric. Water Manag. 10:159-174.

Hulugalle, N., D. Nehl and T. Weaver. 2004. Soil properties, and cotton growth, yield and fibre quality in three cottonbased cropping systems. Soil Till. Res. 75:131-141.

Hulugalle, N.R. and I.G. Daniells. 2005. Permanent beds in Australia cotton production systems. In: C. Roth, R. Fischer and C. Meisner (eds.), Evaluation and performance of permanent raised bed cropping systems in Asia, Australia and Mexico. ACIAR Proceedings No. 121, Griffith, NSW, Australia; pp.162-172.

Jin, H., L. Hongwen, N. Kuhn, Z. Xuemin and L. Wenying. 2007. Soil loosening on permanent raised-beds in arid northwest China. Soil Till. Res. 97:172-183.

Juan, J. A., J. Tarjuelo, M. Valiente and P. Garcia. 1996. Model for optimal cropping patterns within the farm based on crop water production functions and irrigation uniformity I: Development of a decision model. Agric. Water Manag. 31:115-143.

Khatri, K.L. 2007. Toward real-time control of surface irrigation. In: National Centre for Engineering in Agriculture, Uni. of Southern Queensland (USQ), Toowoomba, Qld.

Lucy, M.J. 1993. Permanent wide beds- a controlled traffic system for irrigated vertisols. Information SeriesQueensland, Australia, Department of Primary Industries, Queensland; p.56.

Malhi, S.S., R. Lemke, Z. Wang and B.S. Chhabra. 2006. Tillage, nitrogen and crop residue effects on crop yield, nutrient uptake, soil quality, and greenhouse gas emissions. Soil Till. Res. 90:171-183.

McClymont, D. and R. Smith. 1996. Infiltration parameters from optimization on furrow irrigation advance data. Irrig. Sci. 17:15-22.

McGarry, D. 1993. Degradation of soil structure. In: G.M. Tainsh and W.C. Boughton (eds.), Land Degradation Processes in Australia. Longman Cheshire, Melbourne; pp.271-305.

McGarry, D. 1995. The optimization of soil structure for cotton production. In: G.A. Constable and N.W. Forrester (eds.), Challenging the future. World Cotton Research Conference, Brisbane, Queensland. pp.169-176.

McHugh, A., J. Tullberg and D. Freebairn. 2009. Controlled traffic farming restores soil structure. Soil Till. Res. 104:164-172.

McKenzie, D. C. 1998. SOILpak for cotton growers, $3^{\text {rd }} \mathrm{Ed}$. NSW Agriculture, Orange, NSW, Australia.

Merriam, J.L. and J. Keller. 1978. Farm irrigation system evaluation: a guide for management. Agricultural and irrigation engineering department, Utah State University, Logan.

Roth, C., R. Fischer, C. Piggin and W. Meyer. 2005. Evaluation and performance of permanent raised bed systems in Asia, Mexico and Australia: A synopsis. In: C. Roth, R. Fischer and C. Meisner (eds.), Evaluation and performance of permanent raised bed cropping systems in Asia, Australia and Mexico. ACIAR Proceeding No. 121, Griffith, NSW, Australia; pp.200-208.

Sayre, K., A. Limon and B. Govaerts. 2005. Experiences with permanent bed planting systems CIMMYT, Mexico. In: C. Roth, R. Fischer and C. Meisner (eds.), Evaluation and performance of permanent raised bed cropping systems 
in Asia, Australia and Mexico. ACIAR Proceeding No. 121, Griffith, NSW, Australia; pp.12-25.

Smith, R., S. Raine and J. Minkevich. 2005. Irrigation application efficiency and deep drainage potential under surface irrigated cotton. Agric. Water Manag. 71:117130.

Soane, B. 1976. Studies on some soil physical properties in relation to cultivations and traffic In: Soil physical conditions and crop production. Technical bulletinMinistry of Agriculture, Fisheries and Food, London; pp.249-260.

Solomon, K. 1984. Yield related interpretations of irrigation uniformity and efficiency measures. Irrig. Sci. 5:161172.

Tobias, S. and R. Rickson. 1994. Shear strength of the soil root system: in situ shear tests. In: R. Rickson (ed.), Conserving soil resources: European perspectives. Selected papers from the First International Congress of the European Society for Soil Conservation. CAB International Wallingford United Kingdom; pp.405-412.

Tullberg, J. and S. Murray. 1988. Controlled traffic in subtropical grain production. In: $11^{\text {th }}$ Conference: International Society of Soil and Tillage Research Organization Germany; pp.323-327.
Waldron, L. and S. Dakessian. 1981. Soil reinforcement by roots: calculation of increased soil shear resistance from root properties. Soil Sci. 132:427-435.

Walker, W.R. 2003. Surface irrigation simulation, evaluation and design. User Guide and Technical Documentation. Utah State University, Logan, Utah; p.145.

Wang, X., K. Dai, D. Zhang, X. Zhang, Y. Wang, Q. Zhao, D. Cai, W. Hoogmoed and O. Oenema. 2011. Dryland maize yields and water use efficiency in response to tillage/crop stubble and nutrient management practices in China. Field Crops Res. 120:47-57.

Wang, X., H. Wu, K. Dai, D. Zhang, Z. Feng, Q. Zhao, X. Wu, K. Jin, D. Cai and O. Oenema. 2012. Tillage and crop residue effects on rainfed wheat and maize production in northern China. Field Crops Res. 132:106116.

Wightman, B., R. Peries, C. Bluett and T. Johnston. 2005. Permanent rasied bed cropping in southern Australia: practical guidelines for implementation. In: C.H. Roth, R.A. Fischer and C.A. Meisner (eds.), Evaluation of performance of permanent raised bed cropping systems in Asia, Australia and Mexico. ACIAR Proceeding No. 121, Griffith, NSW, Australia; pp.173-190.

Zhang, H., X. Wang, M. You and C. Liu. 1999. Water-yield relations and water-use efficiency of winter wheat in the North China Plain. Irrig. Sci. 19:37-45. 